\title{
ERS/ELS/ACCP 2013 international consensus conference nomenclature on inducible laryngeal obstructions
}

\author{
Pernille M. Christensen ${ }^{1}$, John-Helge Heimdal ${ }^{2}$, Kent L. Christopher ${ }^{3}$, \\ Caterina Bucca ${ }^{4}$, Giovanna Cantarella ${ }^{5}$, Gerhard Friedrich ${ }^{6}$, Thomas Halvorsen ${ }^{7}$, \\ Felix Herth ${ }^{8}$, Harald Jung ${ }^{9}$, Michael J. Morris ${ }^{10}$, Marc Remacle ${ }^{11}$, \\ Niels Rasmussen ${ }^{12,13}$ and Janet A. Wilson ${ }^{14}$ on behalf of the ERS/ELS/ACCP \\ Task Force on Inducible Laryngeal Obstructions
}

\begin{abstract}
Affiliations: 'Danish Paediatric Pulmonary Service, Rigshospitalet, University of Copenhagen, Copenhagen, Denmark. ${ }^{2}$ Dept of Otolaryngology, Haukeland University Hospital, Bergen, Norway. ${ }^{3}$ Dept of Medicine, University of Colorado School of Medicine, Denver, CO, USA. ${ }^{4}$ Dept of Medical Sciences, University of Turin, Turin, Italy. ${ }^{5}$ Dept of Otolaryngology, Fondazione IRCCS Ca' Granda Ospedale Maggiore Policlinico, Milan, Italy. ${ }^{6}$ Dept of Phoniatrics, Speech and Swallowing, Ear, Nose and Throat University Hospital, Medical University of Graz, Graz, Austria. ${ }^{7}$ Dept of Pediatrics, Haukeland University Hospital, Bergen, Norway. ${ }^{8}$ Thoraxklinik, University of Heidelberg, Heidelberg, Germany. ${ }^{9}$ Hochgebirgsklinik Davos, Clinic of Pulmonology/Allergy, Davos, Switzerland. ${ }^{10}$ Dept of Internal Medicine, Brooke Army Medical Center, Houston, TX, USA. ${ }^{11}$ Dept of ORL-Head and Neck Surgery, Louvain University Hospital of Mont-Godinne, Yvoir, Belgium. ${ }^{12}$ Dept of Otorhinolaryngology, Head and Neck Surgery and Audiology, Rigshospitalet, University of Copenhagen, Copenhagen, Denmark. ${ }^{13}$ Faculty of Health and Medical Sciences, University of Copenhagen, Copenhagen, Denmark. ${ }^{14}$ Dept of Otolaryngology Head and Neck Surgery, Newcastle University and Freeman Hospital, Newcastle upon Tyne, UK.
\end{abstract}

Correspondence: Pernille M. Christensen, Danish Pediatric Pulmonary Center, Rigshospitalet, 5003 Blegdamsvej 9, 2100 Copenhagen E, Denmark. E-mail: p.christensenadadlnet.dk

ABSTRACT Individuals reporting episodes of breathing problems caused by re-occurring variable airflow obstructions in the larynx have been described in an increasing number of publications, with more than 40 different terms being used without consensus on definitions. This lack of an international consensus on nomenclature is a serious obstacle for the development of the area, as knowledge from different centres cannot be matched, pooled or readily utilised by others. Thus, an international Task Force has been created, led by the European Respiratory Society/European Laryngological Society/American College of Chest Physicians. This review describes the methods used to reach an international consensus on the subject and the resulting nomenclature, the 2013 international consensus conference nomenclature.

@ERSpublications

The condition leading to episodes of feeling like you cannot breathe now has a name: inducible laryngeal obstructions http://ow.ly/OMaNl

\section{Introduction}

Individuals reporting episodes of breathing problems caused by recurring variable airflow obstructions in the larynx have been described in an increasing number of publications.

Received: Aug 282013 | Accepted after revision: Oct 072013

Support statement: The Task Force received a grant from the ERS to cover secretarial costs and subsistence during meetings. Travel and accommodation expenses for ERS members of the Task Force, in connection with the Copenhagen meeting, were also covered by the grant.

Conflict of interest: Disclosures can be found alongside the online version of this article at err.ersjournals.com

Provenance: Submitted article, peer reviewed.

Copyright OERS 2015. ERR articles are open access and distributed under the terms of the Creative Commons Attribution Non-Commercial Licence 4.0. 
Despite the occurrence of common traits and clear laryngoscopic features, more than 40 different nomenclatures have been employed [1-43].

The terminology is, to say the least, confusing. On the one hand, similar laryngoscopic findings and/or symptomatology (e.g. onset/termination of attacks post-exposure, inducers of attacks, causation and patient demographics) have been described with different terms $[4,7,14,17,22,28,29,37,44-46]$, while on the other hand the same nomenclature has been used to describe differing clinical features [47-52]. This lack of an international consensus on nomenclature prevents research and expertise from different centres from being matched, pooled or readily utilised by others and effectively hampers progress in the area.

Due to this, a committee on exercise-induced laryngeal obstruction was initially created by the European Laryngological Society. To expand the reach beyond exercise as an inducer and to include a greater variety of experts an international Task Force led the European Respiratory Society (ERS)/European Laryngological Society (ELS), with subsequent inclusion of the American College of Chest Physicians (ACCP), was created. This report describes the methods used to achieve an interdisciplinary and international consensus on relevant nomenclature, which has been termed the 2013 international consensus conference nomenclature.

\section{Process of creating the consensus}

A review of the literature was performed to identify variations of conditions and an initial discussion on nomenclature took place at the 2010 ELS conference in Vienna, Austria. Once approved (on October 13, 2010), the Task Force met in Copenhagen, Denmark, on April 7-8, 2011, where variations of the conditions were discussed based on: 1) laryngoscopic recordings of cases collected by the Task Force members; 2) cases/studies described in the literature following an extensive PubMed search using the keywords vocal cord dysfunction, paradoxical vocal fold motion, and exercise induced laryngomalacia; and 3) reviews of references identified and articles collected by Task Force members over the years.

The literature review and case discussion made it clear that we are faced with a variety of conditions with varying laryngoscopic findings, symptomatology and aetiology sharing common traits. Based on the common traits a definition and an umbrella term to cover the group of conditions were agreed upon. A system for sub-categorisation was also agreed upon, in order to improve understanding and clarify future research initiatives.

A draft for the consensus report was completed based on these agreements and was revised and approved by all members of the Task Force. The article was then submitted to each of the societies for further scrutiny. Once the article had been pre-approved by all three societies it was submitted for publication.

\section{The proposed nomenclature}

Name of nomenclature: 2013 international consensus conference nomenclature.

Definition of the group of conditions: inducible laryngeal obstructions causing breathing problems.

Umbrella term for the group of conditions: Ilo.

System of sub-categorisation: as very little is scientifically proven in this area and the variety of conditions are not fully known it was agreed that any condition within the umbrella term should be named using descriptive terms rather than set names. As knowledge grows we envision an expansion of the classification system. At present only two domains are mandatory in describing a case or condition under study. These two domains are described below.

\section{The inducer}

This is the mechanism by which the individual episode of laryngeal obstruction causing breathing problems is manifested. The following must be described. 1) Identify the inducer of the individual episode, e.g. exercise, emotional stress and irritant. It is recognised that in some cases the inducer may not be readily identified. In these cases this must be clearly stated. 2) Specify the event by which the subject is exposed to the inducer, e.g. high-intensity training, competitive sporting event, domestic argument or exposure to cigarette smoke. It is recognised that in some cases an associated event may not be readily identified. In these cases this must be clearly stated. 3) Specify the time relationship of the onset of the episode (breathing problems) to the exposure of the inducer, e.g. during the exposure, within a few minutes post-exposure, several hours post-exposure, sporadic/unpredictable, etc. No response is needed if an inducer is not readily identifiable. 


\section{Laryngoscopic findings}

Certain points must be covered in the description of laryngoscopic findings, including the circumstances under which they were obtained. The laryngeal features change from baseline to the point of maximal obstruction. Furthermore, in cases of combined supraglottic and glottic involvement the two levels of obstruction may not be co-temporal throughout the attack. Therefore, it is imperative that the exact circumstances for diagnostic laryngoscopy and the choice of laryngoscopic images to be described for sub-category are reported in detail. For multilevel obstruction, each component level requires a separate description. With regards to the laryngoscopic images for specific sub-category description, the following must be reported.

1) The location of the obstruction, i.e. supraglottic (the arytenoid regions, epiglottis or false vocal folds), glottic (the true vocal folds) or both supraglottic and glottic. Note that according to ELS consensus, vocal fold is used instead of vocal cord. 2) The phase of the respiratory cycle during which the obstruction is present, i.e. inspiratory, expiratory or both inspiratory and expiratory. 3) The onset of the laryngoscopically visible obstruction, i.e. fast onset from one breath to the next or slow onset over several breaths. 4) The resolution of the laryngoscopically visible obstruction after cessation of exposure to the inducer (if the obstruction becomes visible during exposure), i.e. fast resolution within 5 min or slow resolution taking $>5$ min. Note that in cases where 3) and 4) cannot be observed this must be clearly stated and the reason given.

The descriptive terms should be given in the following order: inducer of the single attack followed by the umbrella term and then the description of the laryngoscopic findings, e.g. exercise-induced Ilo glottic, inspiratory, fast onset, fast resolution type. In case of an obstruction at both the supraglottic and glottic levels, the obstructive level at onset must be mentioned first, e.g. exercise-induced Ilo supraglottic, inspiratory, slow onset, fast resolution type with a glottic, inspiratory, fast onset, fast resolution type occurring after the onset of the supraglottic obstruction. A summary of the nomenclature structure is presented in table 1 .

\section{Excluded mimics of $/ l o$}

Certain conditions with laryngoscopic evidence of recurring variable obstruction of the larynx will not fall under the umbrella term. These conditions can be obstruction in the airways distal to the larynx (such as tracheomalacia), tracheal stenosis and asthma [53-55].

Laryngeal spasm is a well-described response to mechanical stimulation of the laryngeal mucosa, such as intubations and aspiration, which results in breathing problems [56-58]. When the mucosa is stimulated the true, as well as the false, vocal folds will swiftly adduct causing an instantaneous complete obstruction of the larynx, which may last for variable periods of time depending on the nature of the stimulus [58].

\section{Debate and discussion}

We must acknowledge the limited scientific base of the area due to the equally limited list of studies with laryngoscopic verification. Therefore, in agreeing the nomenclature, it was stressed that the nomenclature had to be flexible in order to remain mutable as the scientific base grows (i.e. not carry any suggestions of underlying causes), yet without compromising the present necessity for a clear and very specific description to allow research to evolve.

For the core definition, we focussed on common traits described throughout the published cases and studies that could be used to identify the patient without making assumptions on underlying causes. These common traits are: 1) the attack-like or varying nature of conditions; 2) the location of the airflow limitation; and 3) the primary symptoms being breathing problems. These are described as "inducible", "laryngeal obstruction" and "causing breathing problems" within the definition.

\section{Inducible}

The attack-like or varying nature of the conditions is incorporated in the published literature as episodic, inducible, factitious, functional, hysterical, intermittent, paradoxical, recurrent or variable. The terms

\section{TABLE 12013 international consensus conference nomenclature}

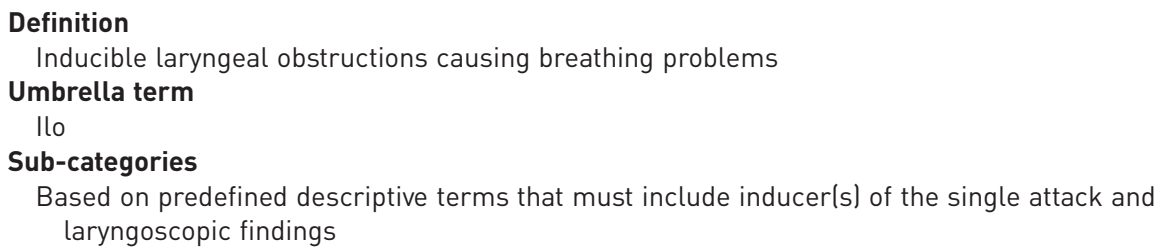


factitious, hysterical and functional were all rejected by the Task Force as they assume a psychogenic basis. Although it is clear that some of the cases have a psychogenic cause, this is not true for all the sub-categories and, thus, the term is not appropriate for the generic definition. The term paradoxical also has, when translated into some languages, a psychogenic connotation. Furthermore, it would not convey the distinction between physiological vocal fold expiratory closure and abnormal "expiratory glottic Ilo". Episodic, recurrent, variable and intermittent suggest a randomness of the conditions, and were rejected. Although there are some cases where an inducer cannot be readily identified [59-61], something, either known or unknown and intrinsic or extrinsic, has to cause the change in the larynx between asymptomatic and symptomatic periods. The term inducible, however, infers the existence of underlying mechanisms that differentiate symptomatic from asymptomatic periods, yet is free from assumptions on causation. "Inducible" was, therefore, chosen to describe the attack-like/varying nature of the conditions, as well as to underline to both patients and professionals that an underlying cause does exist, even in cases where an inducer of the single attack may not be readily identified.

\section{Laryngeal obstruction}

The location of the airflow restriction is not confined to either the vocal folds or the supraglottic structures, but is limited to the larynx. As to the biomechanics of the airflow limitation, several terms have been used in the literature, including: dysfunction, paradoxical motion or movement, dyskinesia/ dyskinesis, adduction, constriction, malfunction, nonorganic obstruction, functional paralysis, spasm and obstruction. Some of these suggest an active process (adduction, constriction and spasm), while others imply a psychogenic pathogenesis (paradoxical motion/movement, functional paralysis and nonorganic obstruction). Dyskinesia/dyskinesis suggests that the conditions are abnormal, however, it says nothing about the nature of the abnormality i.e. airflow limitation. This leaves dysfunction, malfunction and simply obstruction. The phrase "causing breathing problems" incorporates the less specific terms dysfunction and malfunction. Therefore, use of "laryngeal obstruction" to describe the location and type of airflow disturbance was agreed to be sufficient and clear.

\section{Breathing problems}

We opted to include the primary symptoms in the definition in order to exclude physiological variations, and to highlight the importance of Ilo to respiratory physicians. We agreed to use a generally descriptive term as opposed to more specific symptoms. Different terms could have been used such as respiratory distress/problems or dyspnoea. However, when translated into various languages, these terms have different meanings with regards to the severity of the symptom and/or the specificity of the symptom. Breathing problems do not have this linguistic variation and include more specific symptoms, e.g. stridor.

\section{Further considerations}

Some conditions mimic Ilo. These include expiratory vocal fold closure seen in asthmatics [55], where the glottis seemingly functions as an internal positive expiratory pressure generator. However, as this closure is not the cause of the breathing problems, but rather a protective, compensatory posture against lower airway collapse, this does not constitute an Ilo. If the vocal fold closure persists in spite of optimal treatment of asthma it is possible that the patient has an additional, expiratory glottic Ilo. Expiratory vocal fold closure has also been mimicked by other distal airflow limitations, such as tracheal stenosis. Certain laryngeal obstructions are constant but do not cause symptoms until the ventilatory requirements reach a critical point. In these cases the obstruction is not inducible, although the symptoms are. For example, in vocal fold paralysis an increased obstruction may be seen due to the Bernoulli effect during increased ventilation. This should not be classified as an Ilo, but as a mimic, as the underlying fixed obstruction is the key abnormality, even though this is exacerbated in circumstances of high airflow. Laryngeal spasms are also mimics as they are inducible laryngeal obstructions and cause breathing problems; however, they are physiological responses to visceral sensory stimulation such as mucus, blood or touching the mucosa of the larynx with a probe (e.g. a laryngoscope) [56].

110

This brings us to the umbrella term. The criteria for the term were that it had to be short and unassuming. Four possible sources were discussed: a word from ancient Greek or Latin, a neologism, an acronym or a phrase. As a definition was set, a phrase became unnecessary. Abbreviations are not acceptable in certain publications, known words are often loaded with associations and couching conditions in classical terminology is outmoded. Therefore, we agreed to create a neologism from the acronym of "inducible laryngeal obstructions", namely Ilo. It was felt it met the criteria and would be easily remembered, as well as being associated with the definition. 
With an umbrella term and a set definition based on the known (i.e. common) traits the sub-categorising was more challenging. We do not know if we are faced with fundamentally different sub-groups or if the conditions are simply manifestations of the same basic causation. Two methods of sub-categorising were discussed: a hierarchy and a flat matrix. A hierarchy suggests certain associations depending on the layers of the hierarchy (i.e. the parts which differ between the sub-groups), however, we do not have enough knowledge to determine such associations. A flat matrix does not make such assumptions and is more flexible. It allows for and invites research to complete the network of associations between the different sub-categories as opposed to the more rigid system of a hierarchy.

At present we do not know enough to require more than the description of inducers and laryngoscopic findings. The patient's own description of the circumstances of the episodes gives the inducers (one or more, if readily identifiable) and the laryngoscopic findings simply verify the presence of a laryngeal obstruction. Therefore, these two points make no assumptions on aetiology. As the scientific base grows we shall try to establish how to reduce or augment the sub-classification matrix.

With this new international consensus on nomenclature a general streamlining of future research will be possible as we can match, pool and readily use results from different centres. A revision of the published literature will also be possible to identify and critically review present publications to clarify exactly how much, or how little, evidence we have and where research is seriously lacking.

\section{References}

1 Appelblatt N, Baker SR. Functional upper airway obstruction. A new syndrome. Arch Otolaryngol 1981; 107: 305-306.

2 Archer GJ, Hoyle JL, McCluskey A, et al. Inspiratory vocal cord dysfunction, a new approach in treatment. Eur Respir J 2000; 15: 617-618.

3 Balasubramaniam SK, O'Connell EJ, Sachs MI, et al. Recurrent exercise-induced stridor in an adolescent. Ann Allergy 1986; 57: 287-288.

4 Barnes SD, Grob CS, Lachman BS, et al. Psychogenic upper airway obstruction presenting as refractory wheezing. J Pediatr 1986; 109: 1067-1070.

5 Björnsdóttir US, Gudmundsson $\mathrm{K}$, Hjartarson $\mathrm{H}$, et al. Exercise-induced laryngochalasia: an imitator of exercise-induced bronchospasm. Ann Allergy Asthma Immunol 2000; 85: 387-391.

6 Chawla SS, Upadhyay BK, MacDonnell KF. Laryngeal spasm mimicking bronchial asthma. Ann Allergy 1984; 53: 319-321.

7 Christopher KL, Wood RP, Eckert RC, et al. Vocal-cord dysfunction presenting as asthma. N Engl J Med 1983; 308: 1566-1570.

8 Chung KF. Laryngeal stridor during acute asthma. Lancet 1982; 2: 767

9 Clinical Conferences at The Johns Hopkins Hospital. Upper airway obstruction in asthma. Johns Hopkins Med J 1980; 147: 233-237.

10 Collett PW, Brancatisano T, Engel LA. Spasmodic croup in the adult. Am Rev Respir Dis 1983; 127: 500-504.

11 Dinulos JG, Karas DE, Carey JP, et al. Paradoxical vocal cord motion presenting as acute stridor. Ann Emerg Med 1997; 29: 815-817.

12 Downing ET, Braman SS, Fox MJ, et al. Factitious asthma. Physiological approach to diagnosis. JAMA 1982; 248: 2878-2881.

13 Echternach M, Delb W, Verse T, et al. Does isolated expiratory vocal cord dysfunction exist? Otolaryngol Head Neck Surg 2008; 138: 805-806.

14 Ferris RL, Eisele DW, Tunkel DE. Functional laryngeal dyskinesia in children and adults. Laryngoscope 1998; 108 : $1520-1523$

15 Gessler EM, Simko EJ, Greinwald JH Jr. Adult laryngomalacia: an uncommon clinical entity. Am J Otolaryngol 2002; 23: 386-389.

16 Guntupalli KK, Bandi V, Sirgi C, et al. Usefulness of flow volume loops in emergency center and ICU settings. Chest 1997; 111: 481-488.

17 Heatley DG, Swift E. Paradoxical vocal cord dysfunction in an infant with stridor and gastroesophageal reflux. Int J Pediatr Otorh 1996; 34: 149-151.

18 Heimdal JH, Roksund OD, Halvorsen T, et al. Continuous laryngoscopy exercise test: a method for visualizing laryngeal dysfunction during exercise. Laryngoscope 2006; 116: 52-57.

19 Heinle R, Linton A, Chidekel AS. Exercise-induced vocal cord dysfunction presenting as asthma in pediatric patients: toxicity of inappropriate inhaled corticosteroids and the role of exercise laryngoscopy. Pediatr Asthma Allergy Immunol 2003; 16: 215-224.

20 Heiser JM, Kahn ML, Schmidt TA. Functional airway obstruction presenting as stridor: a case report and literature review. J Emerg Med 1990; 8: 285-289.

21 Kivity S, Bibi H, Schwarz Y, et al. Variable vocal cord dysfunction presenting as wheezing and exercise-induced asthma. J Asthma 1986; 23: 241-244.

22 Liistro G, Stănescu D, Dejonckere P, et al. Exercise-induced laryngospasm of emotional origin. Pediatr Pulmonol 1990; 8: 58-60.

23 Maat RC, Roksund OD, Halvorsen T, et al. Audiovisual assessment of exercise-induced laryngeal obstruction: reliability and validity of observations. Eur Arch Otorhinolaryngol 2009; 266: 1929-1936.

24 McClean SP, Lee JL, Sim TC, et al. Intermittent breathlessness. Ann Allergy 1989; 63: 486-488.

25 McNally P, Greally P. Use of post-exercise laryngoscopy to evaluate exercise induced dyspnea. Pediatr Pulmonol 2010; 45: 1037-1039.

26 Mobeireek A, Alhamad A, Al-Subaei A, et al. Psychogenic vocal cord dysfunction simulating bronchial asthma. Eur Respir J 1995; 8: 1978-1981. 
Mullinax MC, Kuhn WF. Benign paradoxical vocal cord adduction presenting as acute stridor. Eur J Emerg Med 1996; 3: 102-105.

Myears DW, Martin RJ, Eckert RC, et al. Functional versus organic vocal cord paralysis: rapid diagnosis and decannulation. Laryngoscope 1985; 95: 1235-1237.

Perkner JJ, Fennelly KP, Balkissoon R, et al. Irritant-associated vocal cord dysfunction. J Occup Env Med 1998; 40: 136-143.

Pinho SM, Tsuji DH, Sennes L, et al. Paradoxical vocal fold movement: a case report. J Voice 1997; 11: 368-372.

Ramirez J, Leon I, Rivera LM. Episodic laryngeal dyskinesia. Clinical and psychiatric characterization. Chest 1986; 90: 716-721.

Richter GT, Rutter MJ, deAlarcon A, et al. Late-onset laryngomalacia: a variant of disease. Arch Otolaryngol Head Neck Surg 2008; 134: 75-80.

Rodenstein DO, Francis C, Stănescu DC. Emotional laryngeal wheezing: a new syndrome. Am Rev Respir Dis 1983; 127: 354-356.

4 Rogers JH, Stell PM. Paradoxical movement of the vocal cords as a cause of stridor. J Laryngol Otol 1978; 92: 157-158.

Sim TC, McClean SP, Lee JL, et al. Functional laryngeal obstruction: a somatization disorder. Am J Med 1990; 88: 293-295.

Skinner DW, Bradley PJ. Psychogenic stridor. J Laryngol Otol 1989; 103: 383-385.

Smith ME, Darby KP, Kirchner K, et al. Simultaneous functional laryngeal stridor and functional aphonia in an adolescent. Am J Otolaryngol 1993; 14: 366-369.

Smith RJ, Bauman NM, Bent JP, et al. Exercise-induced laryngomalacia. Ann Otol Rhinol Laryngol 1995; 104: 537-541.

Snyder HS, Weiss E. Hysterical stridor: a benign cause of upper airway obstruction. Ann Emerg Med 1989; 18: 991-994.

Tervonen H, Niskanen MM, Sovijärvi AR, et al. Fiberoptic videolaryngoscopy during bicycle ergometry: a diagnostic tool for exercise-induced vocal cord dysfunction. Laryngoscope 2009; 119: 1776-1180.

Tousignant G, Kleiman SJ. Functional stridor diagnosed by the anaesthetist. Can J Anaesth 1992; 39: 286-289.

Wood RP 2nd, Jafek BW, Cherniack RM. Laryngeal dysfunction and pulmonary disorder. Otolaryngol Head Neck Surg 1986; 94: 374-378.

Young O, Russell JR. Suture lateralization of vocal cord treating paradoxical vocal cord movement: a case report. Eur Arch Otorhinolaryngol 2008; 265: 485-487.

4 Daminda DA, Jayasooriya C, Wijekoon PN. Refractory wheezing: paradoxical vocal cord motion. Ceylon Med J 2007; 52: 137-138.

Kivity S, Souhrada JF. Hyperpnea: the common stimulus for bronchospasm in asthma during exercise and voluntary isocapnic hyperpnea. Respiration 1980; 40: 169-177.

Warburton CJ, McL Niven R, Higgins BG, et al. Functional upper airways obstruction: two patients with persistent symptoms. Thorax 1996; 51: 965-966.

Allan PF, Abouchahine S, Harvis L, et al. Progressive vocal cord dysfunction subsequent to a chlorine gas exposure. $J$ Voice 2006; 20: 291-296.

Juliá JC, Martorell A, Armengot MA, et al. Vocal cord dysfunction in a child. Allergy 1999; 54: 748-751.

Landwehr LP, Wood RP, Blager FB, et al. Vocal cord dysfunction mimicking exercise-induced bronchospasm in adolescents. Pediatrics 1996; 98: 971-974.

Walaschek C, Forster J, Echternach M. Vocal cord dysfunction without end? Klin Padiatr 2010; 222: 84-85.

Weir M. Vocal cord dysfunction mimics asthma and may respond to heliox. Clin Pediatr (Phila) 2002; 41: 37-41.

Zelcer S, Henri C, Tewfik TL, et al. Multidimensional voice program analysis (MDVP) and the diagnosis of pediatric vocal cord dysfunction. Ann Allergy Asthma Immunol 2002; 88: 601-608.

3 Collett PW, Brancatisano AP, Engel LA. Upper airway dimensions and movements in bronchial asthma. Am Rev Respir Dis 1986; 133: 1143-1149.

Higenbottam T, Payne J. Glottis narrowing in lung disease. Am Rev Respir Dis 1982; 125: 746-750.

Hurbis CG, Schild JA. Laryngeal changes during exercise and exercise-induced asthma. Ann Otol Rhinol Laryngol 1991; 100: 34-37.

Fink BR. The etiology and treatment of laryngeal spasm. Anesthesiology 1956; 17: 569-577.

Rex MA. A review of the structural and functional basis of laryngospasm and a discussion of the nerve pathways involved in the reflex and its clinical significance in man and animals. Br J Anaesth 1970; 42: 891-899.

Salem RM, Crystal GJ, Nimmagadda U. Un
treatment. Anesthesiology 2012; 117; 441-442.

Bahrainwala AH, Simon MR, Harrison DD, et al. Atypical expiratory flow volume curve in an asthmatic patient with vocal cord dysfunction. Ann Allergy Asthma Immunol 2001; 86: 439-443.

Craig T, Sitz K, Squire E, et al. Vocal cord dysfunction during wartime. Mil Med 1992; 157: 614-616.

Fields CL, Roy TM, Ossorio MA. Variable vocal cord dysfunction: an asthma variant. South Med J 1992; 85: $422-424$. 